\title{
Higher Weight Variability Could Bring You a Fatty Liver
}

\author{
Yeoree Yang ${ }^{1,2}$ Jae-Hyoung Cho ${ }^{1,2}$
}

${ }^{1}$ Division of Endocrinology and Metabolism, Department of Internal Medicine, Seoul St. Mary's Hospital, College of Medicine, The Catholic University of Korea; ${ }^{2}$ Catholic Smart Health Care Center, College of Medicine, The Catholic University of Korea, Seoul, Korea

Obesity, one of the most leading global health burdens of the 21 st century, is defined as disproportionate body weight for one's height together with excess body fat accumulation, usually accompanied by systemic inflammation [1]. Nonalcoholic fatty liver disease (NAFLD) is a spectrum of disease encompassing hepatic fat accumulation, ranging from hepatocyte inflammation and necrosis to fibrosis and cirrhosis. Occurring in the background of obesity and insulin resistance, NAFLD is associated with various metabolic and cardiovascular disorders, such as metabolic syndrome, hypertension, dyslipidemia, and type 2 diabetes, as well as progressive liver disease [2]. There is currently no approved pharmacotherapy for NAFLD; the first priority of treatment is weight loss through lifestyle changes [3]. Weight loss can improve not only the hepatic histology, but also metabolic risk factors associated with obesity in a dose-related manner. Nevertheless, weight loss and its long-term maintenance are difficult to achieve, as an estimated $80 \%$ of individuals who intentionally lose more than $10 \%$ body weight regain that weight within a year [4]. This pattern of repetitive weight loss and regain is referred to as weight cycling or weight fluctuation, which could lead to adverse outcomes contrary to the original intention.

Recent studies have shown that weight cycling adversely affects the accumulation and distribution of body fat [5-7]. An increased propensity to regain fat mass after weight loss may be explained by the improved fat storage capacity of adipose tis-

Received: 10 August 2021, Accepted: 15 August 2021

Corresponding author: Jae-Hyoung Cho

Division of Endocrinology and Metabolism, Department of Internal Medicine, Seoul St. Mary's Hospital, College of Medicine, The Catholic University of Korea, 222 Banpo-daero, Seocho-gu, Seoul 06591, Korea

Tel: +82-2-2258-6008, Fax: +82-2-595-2534, E-mail: drhopper@ikoob.com sue. In a study with a rat model of weight recovery, after 1 week of refeeding, insulin-stimulated glucose utilization was lower in skeletal muscle but higher in white adipose tissue, resulting in catch-up fat accumulation [8]. These changes in insulin sensitivity and the increased insulin secretion during refeeding are explained as the main drivers of boosted lipid storage during weight cycling. In contrast, gain in muscle mass can only be achieved through the anabolic effects of a positive energy balance, whereas the large energy deficit during dieting leads to an accelerated loss of lean body mass [9]. In addition to unfavorable body fat accumulation, epidemiologic studies have shown that long-term weight fluctuations are linked to adverse health consequences such as type 2 diabetes, cardiovascular diseases, and mortality [10-12].

In this issue of Endocrinology and Metabolism, Jung et al. [13] published a study investigating the association between weight variability and the NAFLD in subjects without diabetes. The authors observed that subjects with higher weight fluctuations, as assessed by average successive variability and the coefficient of variation of serial weight data, showed an increased risk of developing NAFLD. Interestingly, a stepwise increased risk of NAFLD development was observed according to baseline obesity status and weight variability; the most prominent risks were noted in subjects with higher weight variability and with baseline obesity or weight gain during follow-up. A major strength of this study is that it included relatively young subjects

\section{Copyright $\odot 2021$ Korean Endocrine Society}

This is an Open Access article distributed under the terms of the Creative Commons Attribution Non-Commercial License (https://creativecommons.org/ licenses/by-nc/4.0/) which permits unrestricted non-commercial use, distribution, and reproduction in any medium, provided the original work is properly cited. 
for whom over 4 years of weight data were available, using a well-structured cohort at the Health Promotion Center of Kangbuk Samsung Hospital. Furthermore, study subjects were classified into various groups according to obesity status and weight variability. The consistent findings in the analyses give strong support to the link between weight fluctuation and NAFLD development.

However, we have several concerns related to the interpretation of the results of this study. As mentioned by the authors as a limitation, the cause (intentional or unintentional) and methods (e.g., dieting, exercise, or both) by which weight fluctuations occurred could not be assessed in the study. There might have been heterogeneous causes of weight variability according to baseline obesity status. As expected, subjects with higher weight variability showed more so-called "bad habits," which might have had a greater impact on the development of NAFLD in the study than the weight cycling itself; in particular, the group of subjects with higher weight variability had higher alcohol intake and contained more smokers. These differences might have exaggerated the effects of weight fluctuation on the development of NAFLD in obese subjects. Next, the weight measurements assessed in the study were obtained through regular check-ups, which might not accurately reflect actual weight fluctuations; for instance, people often make efforts to lose weight after a health check-up, but their weight cycling might be masked by weight that is regained before the next check-up. Nevertheless, the fact that this analysis was based on a total of 15,340 relatively young healthy subjects could attenuate these concerns [14].

In summary, higher long-term weight variability was significantly associated with an increased risk of developing NAFLD in subjects without diabetes. Weight cycling is considered to be a metabolic adaptation to weight loss originally contributed to increased survival capacity during alternating periods of feast and famine, but appears to lead to adverse health outcomes in the modern obesity-pandemic period. Weight reduction is a powerful and essential solution to restore the NAFLD, a hepatic manifestation of metabolic syndrome. Developing strategies to maintain weight should be emphasized along with weight loss.

\section{CONFLICTS OF INTEREST}

No potential conflict of interest relevant to this article was reported.

\section{ORCID}

Yeoree Yang https://orcid.org/0000-0003-0990-1502

Jae-Hyoung Cho https://orcid.org/0000-0003-2235-8874

\section{REFERENCES}

1. Schwartz MW, Seeley RJ, Zeltser LM, Drewnowski A, Ravussin E, Redman LM, et al. Obesity pathogenesis: an Endocrine Society Scientific Statement. Endocr Rev 2017;38: 267-96.

2. Rowell RJ, Anstee QM. An overview of the genetics, mechanisms and management of NAFLD and ALD. Clin Med (Lond) 2015;15 Suppl 6:s77-82.

3. Singh S, Osna NA, Kharbanda KK. Treatment options for alcoholic and non-alcoholic fatty liver disease: a review. World J Gastroenterol 2017;23:6549-70.

4. Wing RR, Phelan S. Long-term weight loss maintenance. Am J Clin Nutr 2005;82(1 Suppl):222S-5S.

5. Bosy-Westphal A, Kahlhofer J, Lagerpusch M, Skurk T, Muller MJ. Deep body composition phenotyping during weight cycling: relevance to metabolic efficiency and metabolic risk. Obes Rev 2015;16 Suppl 1:36-44.

6. Cereda E, Malavazos AE, Caccialanza R, Rondanelli M, Fatati G, Barichella M. Weight cycling is associated with body weight excess and abdominal fat accumulation: a cross-sectional study. Clin Nutr 2011;30:718-23.

7. Strychar I, Lavoie ME, Messier L, Karelis AD, Doucet E, Prud'homme D, et al. Anthropometric, metabolic, psychosocial, and dietary characteristics of overweight/obese postmenopausal women with a history of weight cycling: a MONET (Montreal Ottawa New Emerging Team) study. J Am Diet Assoc 2009;109:718-24.

8. Cettour-Rose P, Samec S, Russell AP, Summermatter S, Mainieri D, Carrillo-Theander C, et al. Redistribution of glucose from skeletal muscle to adipose tissue during catchup fat: a link between catch-up growth and later metabolic syndrome. Diabetes 2005;54:751-6.

9. Carbone JW, McClung JP, Pasiakos SM. Skeletal muscle responses to negative energy balance: effects of dietary protein. Adv Nutr 2012;3:119-26.

10. Oh TJ, Moon JH, Choi SH, Lim S, Park KS, Cho NH, et al. Body-weight fluctuation and incident diabetes mellitus, cardiovascular disease, and mortality: a 16-year prospective cohort study. J Clin Endocrinol Metab 2019;104:639-46.

11. Zou H, Yin P, Liu L, Liu W, Zhang Z, Yang Y, et al. Body- 
weight fluctuation was associated with increased risk for cardiovascular disease, all-cause and cardiovascular mortality: a systematic review and meta-analysis. Front Endocrinol (Lausanne) 2019;10:728.

12. Stevens VL, Jacobs EJ, Sun J, Patel AV, McCullough ML, Teras LR, et al. Weight cycling and mortality in a large prospective US study. Am J Epidemiol 2012;175:785-92.

13. Jung I, Koo DJ, Lee MY, Moon SJ, Kwon H, Park SE, et al.
Increased risk of nonalcoholic fatty liver disease in individuals with high weight variability. Endocrinol Metab 2021;36: 845-54.

14. Bosy-Westphal A, Muller MJ. Measuring the impact of weight cycling on body composition: a methodological challenge. Curr Opin Clin Nutr Metab Care 2014;17:396400. 